\title{
Global Evidence on the Determinants of Public Trust in Governments during the COVID-19
}

\author{
Giray Gozgor ${ }^{1,2}$ (DD \\ Received: 4 October 2020 / Accepted: 14 December 2020 / Published online: 5 February 2021 \\ (C) The International Society for Quality-of-Life Studies (ISQOLS) and Springer Nature B.V. 2021
}

\begin{abstract}
Using the Global Behaviors and Perceptions in the COVID-19 Pandemic dataset covering 108,918 respondents from 178 countries, the paper examines the determinants of public trust in governments during the COVID-19. It is found that older and healthy people trust more to their governments. Education is negatively related to trust in governments. The results are robust to consider different measures of trust in government as well as including various controls, such as precautionary behaviors, first-order beliefs, second-order beliefs, and the COVID-19 prevalence in the country. The findings are also valid for countries at different stages of economic development as well to varying levels of globalization, institutional quality, and freedom of the press.
\end{abstract}

Keywords The COVID-19 pandemic · Trust in governments · Global survey data · Economic development $\cdot$ Institutional quality $\cdot$ Freedom of the press

JEL Codes $\mathrm{I} 18 \cdot \mathrm{D} 81 \cdot \mathrm{C} 31 \cdot \mathrm{C} 83$

\section{Introduction}

How does the COVID-19 Pandemic affect confidence in governments all over the world? Public trust is an essential tool for providing good governance in all political systems. Governments, which have a higher level of public trust, can govern effectively (Cooper et al. 2008). Trust in government is a reliable indicator of social capital, and it significantly enhances economic performance via higher efficiency in the coordination, decisions, and regulations (Kwon et al. 2013). Governments should provide security to citizens against unpredictable events. During times of uncertainty, trust between

Giray Gozgor

giray.gozgor@medeniyet.edu.tr

1 Istanbul Medeniyet University, Istanbul, Turkey

2 CESifo, Munich, Germany 
government and individuals is crucial for the social contract to hold between these actors (Toya and Skidmore 2014). People can trust their government if they think that the government has the capacity, expertise, and technical knowledge to make the best decisions for the public interest and welfare. The extent of public trust in governments' ability is also vital to respond effectively to the COVID-19 Pandemic in all around the world.

The current responses to the COVID-19 Pandemic can offer new dimensions for people's trust in governments and informing the public. During the COVID-19 Pandemic, there are wide ranges of protective measures, such as general curfew or partial lockdown, closures of schools, workplaces, public transportation, cancellation of public events, and restrictions on national movements (Hale et al. 2020). There are also various stimulus packages to decrease the adverse economic and social outcomes of the COVID-19 Pandemic (Elgin et al. 2020). Obtaining successful results of economic and social stimulus policies and providing full effect to slow down the rate of outbreaks requires an unprecedented degree of social cohesion and public trust in government during the COVID-19. Furthermore, governments need to be trusted in terms of ending the Pandemic and new measures on the COVID-19, such as testing procedures and tracing programs, or possibly implementation of immunity certification and mass vaccination (Eichenberger et al. 2020). Given this backdrop, this paper focuses on the individual-level Global Behaviors and Perceptions in the COVID-19 Pandemic survey dataset covering 108,918 respondents from 178 countries to find determinants of public trust in governments during the COVID-19 era.

According to the previous literature, there are various potential determinants of public trust in governments. There is a wide variety of age, income, and level of education among countries and these demographic indicators can significantly determine trust in governments (Algan et al. 2016; Christensen and Laegreid 2005; Zhao and $\mathrm{Hu}$ 2017). Gender, marital status, and number of households (having a child or living with parents) can also affect public trust (Alesina et al. 2004; Ulbig 2007). For instance, Christensen and Laegreid (2005) and Zhao and $\mathrm{Hu}$ (2017) show that older people have a higher level of trust in government than younger people since older people can be defined as "collective-oriented." Kim (2010) and Tolbert and Mossberger (2006) observe that males have more trust in government in Japan and the United States, respectively. According to Anderson (2010), individuals with a higher income have higher confidence in government in the United States. However, Zhao and $\mathrm{Hu}$ (2017) find that a higher salary is negatively related to trust in government in China. Overall, the effect of income on trust in government is somehow mixed. ${ }^{1}$ Furthermore, Gronlund and Setala (2007), Norris (1999), and Zhao and Hu (2017) indicate that people with higher education have less trust in government since they look more criticized towards governments. ${ }^{2}$ Overall, individuals' demographic groups can be the main drivers of public trust in government.

\footnotetext{
${ }^{1}$ Following the World Bank's definition of the income levels of countries, we also analyze the effects of demographic indicators on public trust in government for countries at different stages of economic development.

${ }^{2}$ Note that Christensen and Laegreid (2005) find that people with a higher level of education have more trust in government. Therefore, the impact of education on trust in government is also arguable in the empirical literature.
} 
To motivate our findings on the health crisis during the COVID-19 pandemic era, we also include the health conditions, behaviors, beliefs of individuals, and the COVID-19 prevalence in countries. One of the novel findings in this paper is that people with better health conditions trust more their governments all around the world.

Citizens' perceptions of the issues of civil liberties and political rights are also an essential driver of public trust. If there will be a higher level of civil liberties and political rights, people think that they may affect government policies or even they can change the government. Therefore, democracy is positively associated with public trust in the government in general. ${ }^{3}$ Indeed, several papers have found that higher levels of democracy and political rights (strong indicators of institutional quality) lead to a higher level of trust in governments (Ariely 2013; Ezrow and Xezonakis 2011; Levi and Stoker 2000; Norris 1999; Nye Jr. et al. 1997). To address these issues, we divide the countries to re-estimate the regressions, according to their levels of civil liberties and political rights following the dataset of Freedom House (2020a).

In addition to demographic indicators and institutional quality measures, several papers have examined the role of media for trust in government. Most of these papers have found that unofficial and official controls on media significantly affect trust in government (Chen and Sun 2019). However, the impact of media on trust in government can be negative or positive. Specifically, the media malaise hypothesis indicates that a free-press leads to less government trust due to the negative news (Patterson 2009). However, the mobilization hypothesis suggests that mass media enhances the citizens' political interest and participation; and therefore, media increases public trust of the ruling party (Norris 2000). Notably, the countries in whose media is not free, the media uses for shaping political values propaganda and mobilizing voters or citizens (Stockmann and Gallagher 2011). To address these hypotheses and to follow previous findings, we separate the countries to re-estimate the regressions, according to their levels of freedom of the press following the dataset of Freedom House (2020b).

Globalization may also affect trust in the government. According to Algan et al. (2016) and Bergh and Bjørnskov (2011), public trust in government has a positive influence on the size of the welfare state. At this stage, globalization can also positively affect the size of the welfare state, according to the compensation hypothesis introduced by Rodrik (1998). Globalization can also capture the effects of cultural variables, economic policy variables, and technology (such as internet use) (see, e.g., Potrafke 2015). Therefore, globalization is one of the leading indicators for shaping public trust in government. To address the impact of globalization on confidence in governments, we divide the countries to re-estimate the regressions, according to their levels of globalization following the dataset of Gygli et al. (2019).

In this paper, we aim to provide the determinants of public trust in governments during the COVID-19 Pandemic. For this purpose, we use the individual-level survey data in the Global Behaviors and Perceptions in the COVID-19 Pandemic dataset covering 108,918 respondents from 178 countries. To the best of our knowledge, this is the first paper in the literature to determine the drivers of public trust governments during the COVID-19 era. We observe that older and healthy people trust more to their governments. However, education is negatively related to trust in governments. These

\footnotetext{
${ }_{3}^{3}$ Democracy also promotes economic performance (Acemoglu et al. 2019; Gründler and Krieger 2016). Hence there is an indirect positive impact of economic growth on trust in government.
} 
findings are robust to consider different measures of trust in government as well as including various controls for the COVID-19 related policies. These findings are also valid for countries at different stages of economic development as well to varying levels of globalization, civil liberties-political rights, and freedom of the press. We suggest that the drivers of public trust in governments can be crucial for providing full effect to slow down the rate of outbreaks, ending the Pandemic, taking new measures, such as testing procedures and tracing programs, or potentially, mass vaccination.

The rest of the paper is organized as follows. "Data and Empirical Models" section describes the data and the empirical models. "Empirical Findings" section provides empirical findings. "Robustness Checks" section implements additional robustness checks. "Conclusion" section concludes with potential implications.

\section{Data and Empirical Models}

\section{Data Sample and Measuring Global Behaviors and Perceptions in the COVID-19 Pandemic}

In this paper, we use the individual-level survey data covering 108,918 respondents from 178 countries. The original dataset has been provided by Fetzer et al. (2020). The data of Fetzer et al. (2020) have been generated by the snowball sampling method, which includes the survey instruments that were translated into 69 languages. The surveys capture the responses to various questions for the period from March 20, 2020, to April 16, 2020. ${ }^{4}$ One hundred seventy-eight countries of respondents in the survey sample are provided in the Data Appendix Table 9.

In Data Appendix Table 7, we report a summary of the descriptive statistics, including the sources of data. In this paper, inspiring from the definition of Levi and Stoker (2000), we use the two measures of trust in government as the dependent variables (Fetzer et al. 2020): Truthfulness of Government Communication (TGC) and Trust in Government (TIG). Both measures are defined as an index from 1 to 5. The former measure captures the responses to the question, "How much do you trust your country's government to take care of its citizens?" and the latter captures the answers to the question, "How factually truthful do you think your country's government has been about the coronavirus outbreak?"A higher level of the indices indicates a higher trust in governments and a higher truthfulness of governments, respectively. According to Data Appendix Table 7, the mean of the index from responses is around 3, which indicates that respondents are "Neither trust nor distrust" and "Neither truthful nor untruthful" to their governments, respectively.

Our first set of variables represents the personal information and demographic variables (Fetzer et al. 2020). First, we consider age in years in 2020 (based on year of birth), with the mean value of 39 , where the minimum age is 18 and a maximum of $110 .^{5}$ Second is the education, and people in the sample have spent 16 years on their education on average. The third variable is log income, which is measured as a log of monthly household income (before tax in domestic currency). Fourth is the dummy

\footnotetext{
${ }^{4}$ Visit http://www.covid19-survey.org for more information and the detailed descriptions of variables.

${ }^{5}$ Note that the minimum age is 18 ; and therefore, all individuals in the sample are also voters.
} 
variable for marital status (married/co-living $=1$ and single and divorced $=0$ ). Here, $56.3 \%$ of the total people in the sample are married and living together. Fifth is the number of household members, and there are three people on average in the households in the sample. Sixth indicator is the dummy variable for gender (male $=1$ and female and other $=0$ ), and $43.2 \%$ of individuals in the sample identify themselves as male. Finally, we control for a health condition, is the index from 1 to 4 , and it captures responses to "How healthy are you?". A higher level of the index of health condition indicates a higher level of health. The average of the index from responses is around 3, which means that respondents have "good health conditions" in general.

The second set of variables, which are controls, represents the captures of the personal responses to the new type of the COVID-19 Pandemic (Fetzer et al. 2020). First, we consider precautionary behaviors, which describe the behavior of people in the sample for the past week. Specifically, on average, $80.5 \%$ of individuals "stayed at home." $90.9 \%$ of people "did not attend social gatherings," and $75.8 \%$ of them "kept a distance of at least two meters." Besides, $93 \%$ of people declare that "If I had exhibited symptoms of sickness, I would have immediately informed the people around me." Finally, 91.9\% of the total people in the sample "washed their hands more frequently than the month before."

Besides, we control for first-order beliefs and second-order beliefs to capture how scientific statements can affect people's behavior during the COVID-19 Pandemic and their thoughts on the society for the related announcements. For instance, on average, $97.6 \%$ of people in the sample believe that "people in their country should cancel their participation at social gatherings." They think that 68 of 100 people in their country are in line with this statement. Also, $96.7 \%$ of people state that "people in their country should not shake other people's hands." They estimate that 76 of 100 people in their country shares this view. Besides, $81.6 \%$ of people in the sample think that "all shops in your country other than supermarkets, pharmacies, post offices, and gas stations should be closed." They indicate that 59 of 100 people in their country are in line with this view. Finally, $70.5 \%$ of the total people in the sample indicate, "there should be a general curfew in the country." However, they believe that 50 of 100 people in their country shares this view.

Finally, we include the indicators of the COVID-19 prevalence in countries on date respondents participated. Specifically, we include i) confirmed cases, ii) confirmed deaths, and iii) patients recovered. We use the data provided by John Hopkins University, which is introduced by Dong et al. (2020).

Furthermore, we include the Stringency Index for controlling government policies relating to the COVID-19. The Stringency Index measures the government policies, such as closures of schools, workplaces, public transportation, cancellation of public events, public information, and restrictions on national movements. The related data are introduced by Oxford University, and the measure is described in detail by Hale et al. (2020). We suggest that the personal responses, the first-order beliefs, the second-order beliefs, the COVID-19 prevalence, and government policies relating to the COVID-19 can significantly change the effects of demographic and personal information on the measures of public trust in governments in all around the world.

In Data Appendix Table 8, we provide the correlation matrix. It is observed that the correlation between two measures of trust in government is 0.75 . Trust in government is negatively correlated with education and income. Besides, the relationship between indicators of trust in government, and age, being married, the number of household members, identifying the gender as male, and health conditions are favorable. 


\section{Empirical Models}

In this paper, we estimate the following empirical models via the Ordinary Least Squares (OLS) with the robust standard errors (clustered at the country level):

$$
\begin{gathered}
\text { GOV_TRUST }_{i, t}=\alpha_{0}+\alpha_{1} X_{1 i, t}+\alpha_{2} X_{2 i, t}+\alpha_{3} D 1+\alpha_{4} D 2+\varepsilon_{1 i, t} \\
\text { GOV_FACT } T_{i, t}=\beta_{0}+\beta_{1} X_{1 i, t}+\beta_{2} X_{2 i, t}+\beta_{3} D 1+\beta_{4} D 2+\varepsilon_{2 i, t}
\end{gathered}
$$

In Eq. (1) and Eq. (2), GOV_TRUST $T_{i, t}$ and $G O V_{-} F A C T_{i, t}$ are the indices of trust and truthfulness of government in country $i . X_{1 i, t}$ is the "vector of independent variables" (capturing age, education, gender, health condition, income, marital status, and members of the household), which represents the personal information. $X_{2 i, t}$ is the "vector of controls" (including precautionary behaviors, first-order beliefs, second-order beliefs, and the COVID-19 measures in the country), which captures the personal responses to the global Pandemic and the COVID-19 prevalence in countries. Since there could be unobservable factors that also vary across the countries, we include $D 1$ and D2 to capture the country-specific effect and country-specific time-trend, respectively. $\varepsilon_{t}$ represents the error-term in the estimations.

For showing the robustness of the empirical findings, we re-estimated the Eq. (1) and Eq. (2) for the countries at different stages of economic development as well as for countries at the different levels of globalization, institutional quality, and freedom of the press.

\section{Empirical Findings}

\section{All Countries}

The results for all countries are reported in Table 1 . Columns from 1 to 4 reports the findings for $T G C$. In Columns from 5 to 8, the results for $T I G$ are reported. Columns 2 and 6 also consist of the country-effects, and Columns 3 and 7 include the time-trend. The results in Columns 4 and 8 include both the country-effects and the time-trend.

All results indicate that age, being married, the number of households and health conditions increase $T G C$ and $T I G$. Education is negatively related to both $T G C$ and $T I G$. Log income is negatively to $T G C$ and $T I G$. Identifying as male is positively associated with both $T G C$ and $T I G$. However, these results are not robust to consider different measures of government in trust since their coefficients are statistically insignificant when TIG is considered.

The positive impact of age on trust in government is similar to previous findings of Christensen and Laegreid (2005) and Zhao and $\mathrm{Hu}$ (2017). Education is negatively related to trust in governments. This evidence is also in line with previous findings of Gronlund and Setala (2007), Norris (1999), and Zhao and Hu (2017). The results are robust to consider two indicators of trust in governments.

It seems that demographic determinants of public trust in governments do not change during the COVID-19 crisis. It is important to emphasize that we provide the first evidence for showing the positive effects of the health condition of trust in governments in the COVID-19 era. 


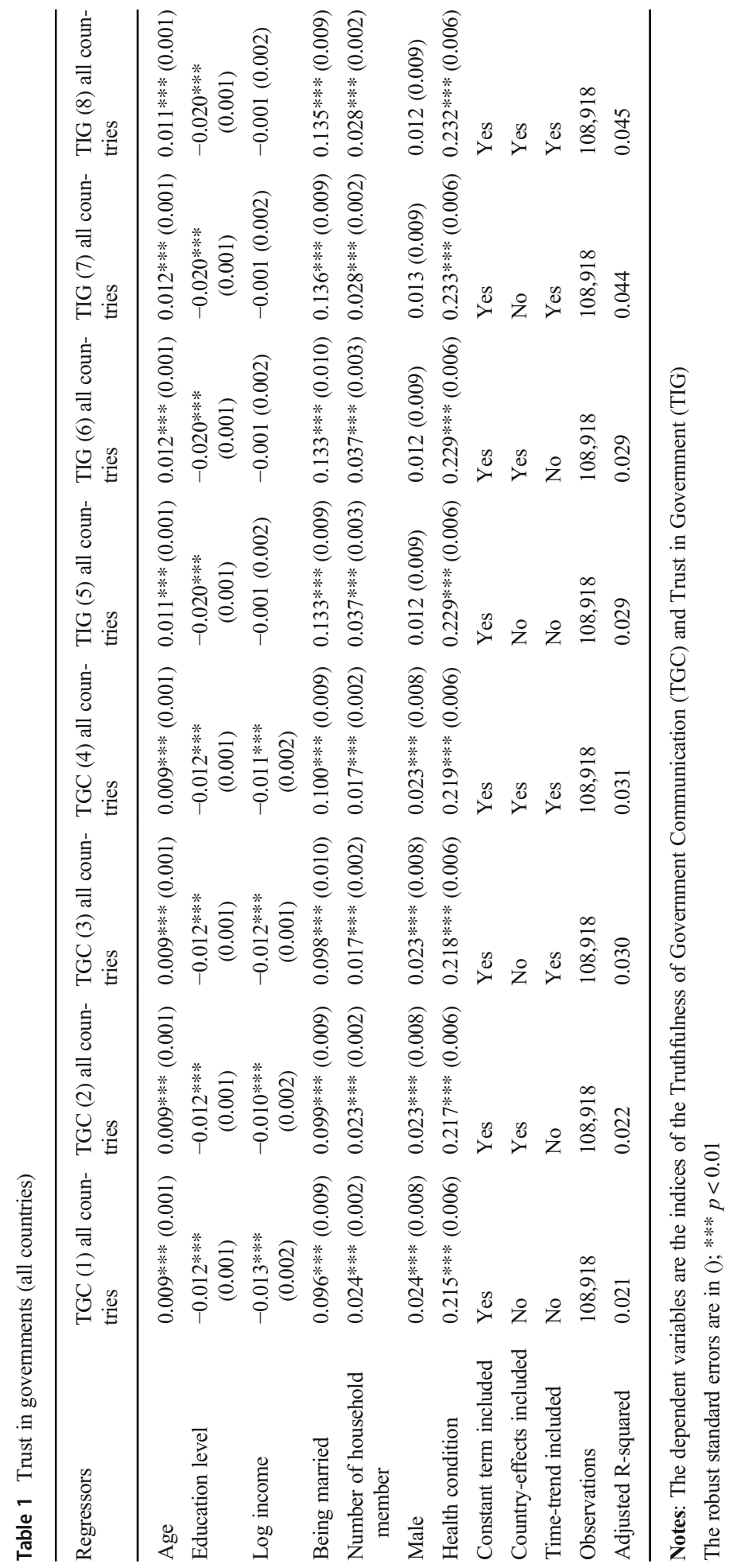




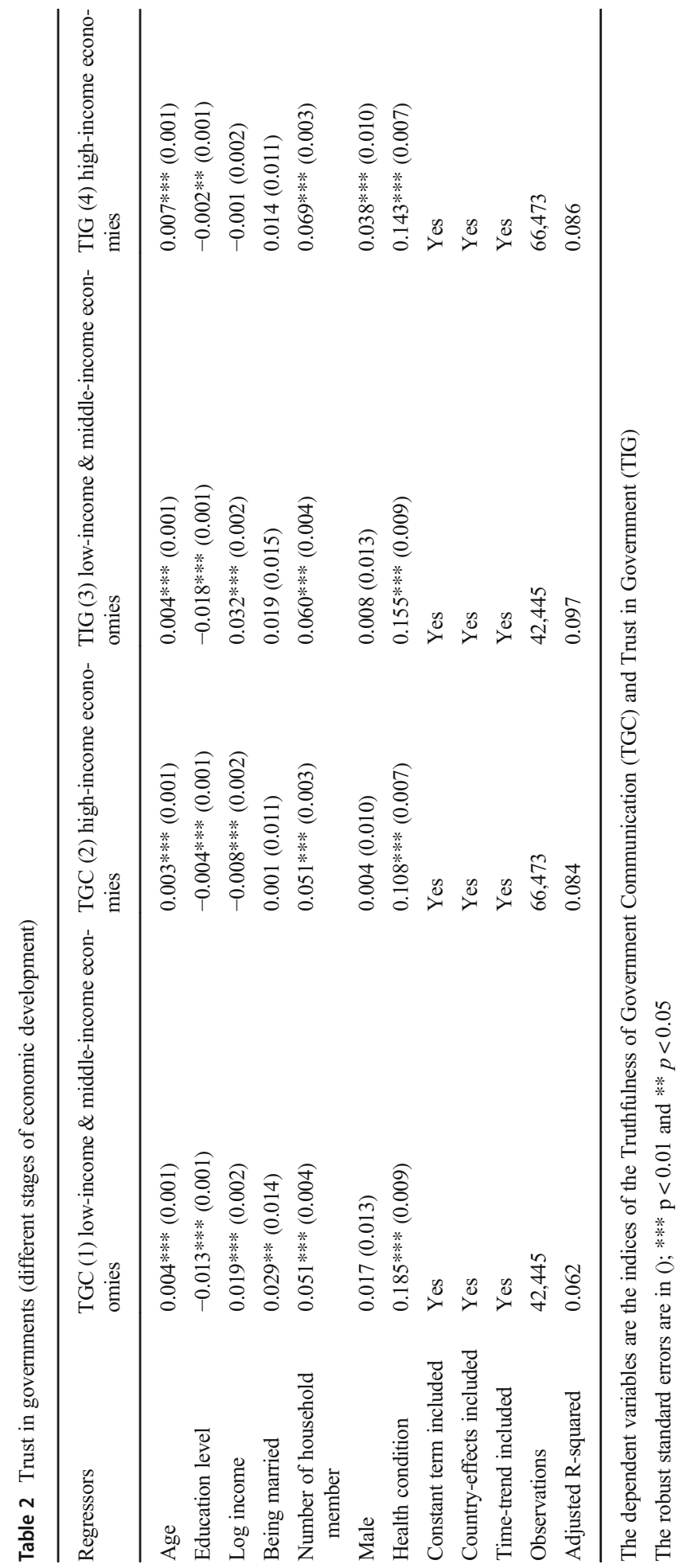




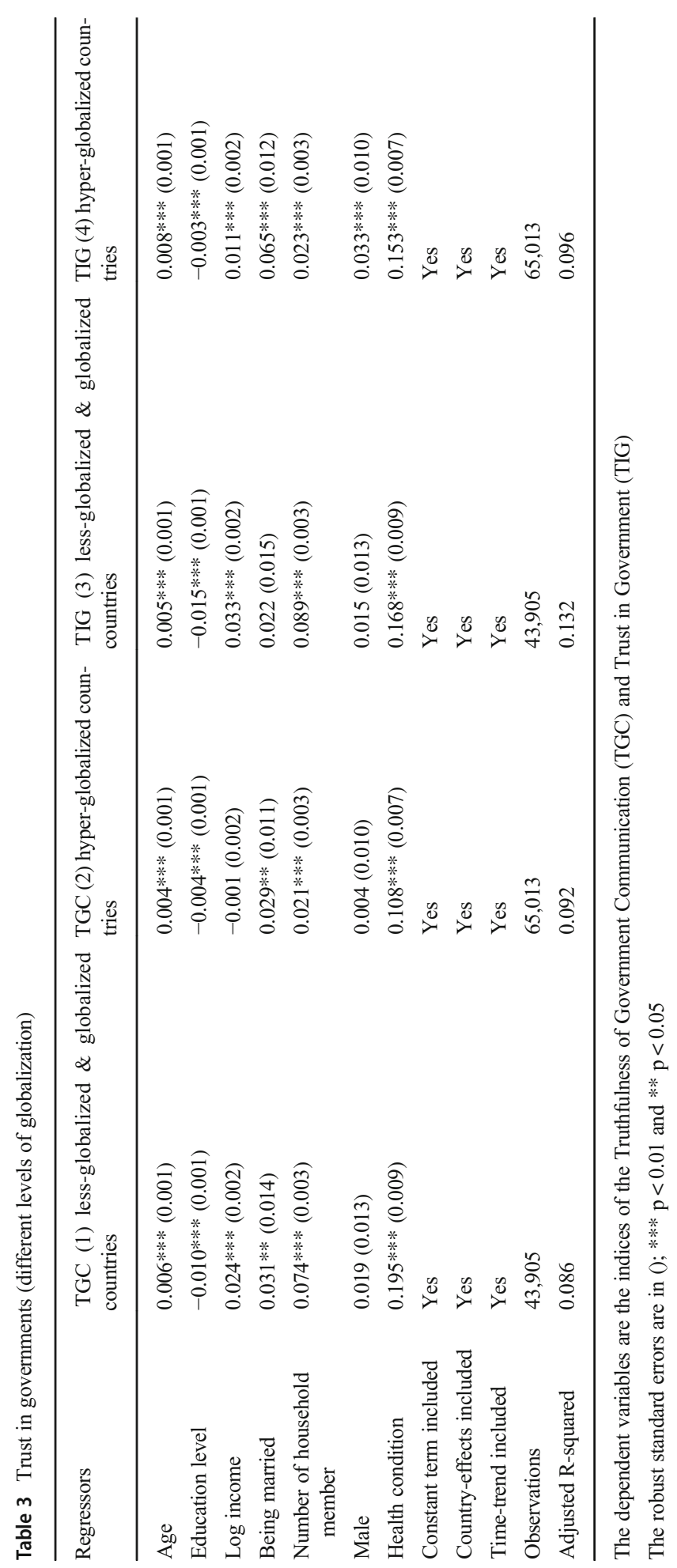




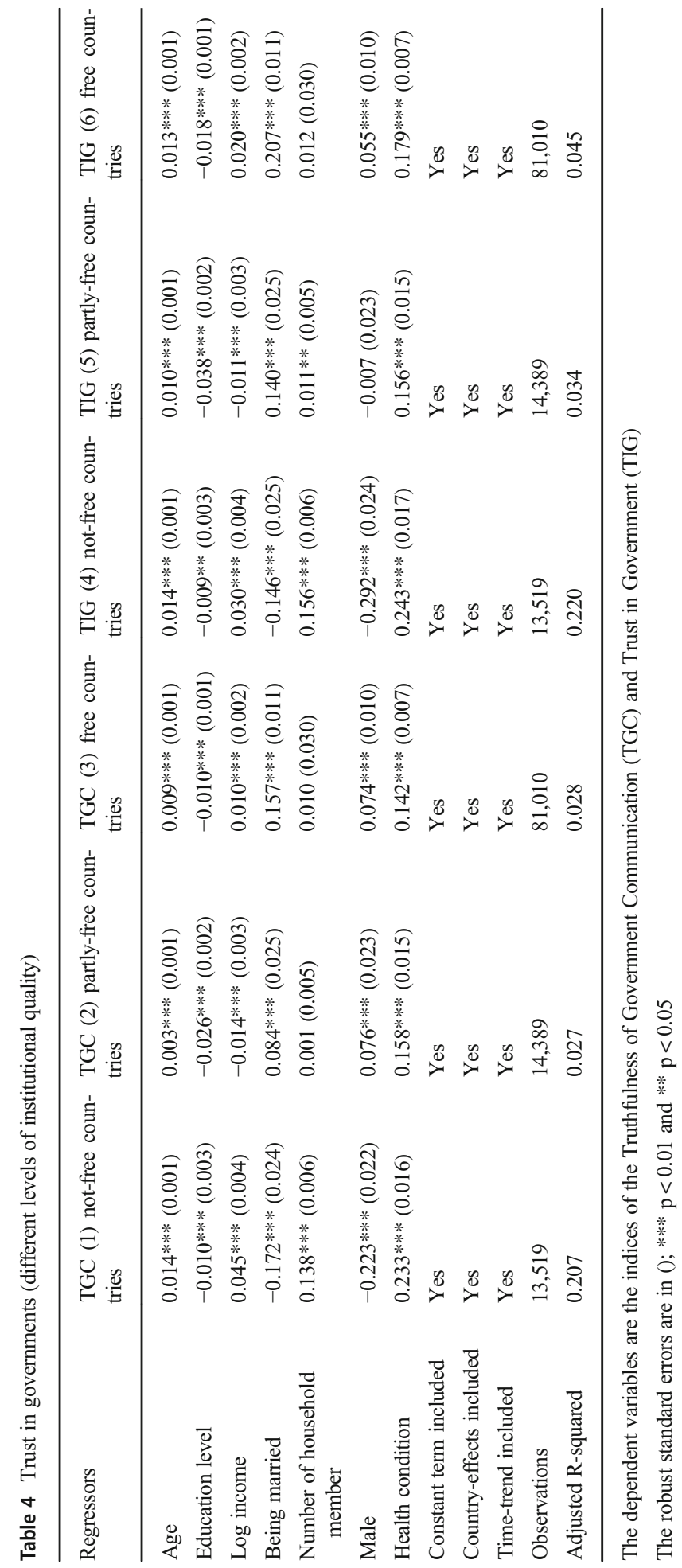




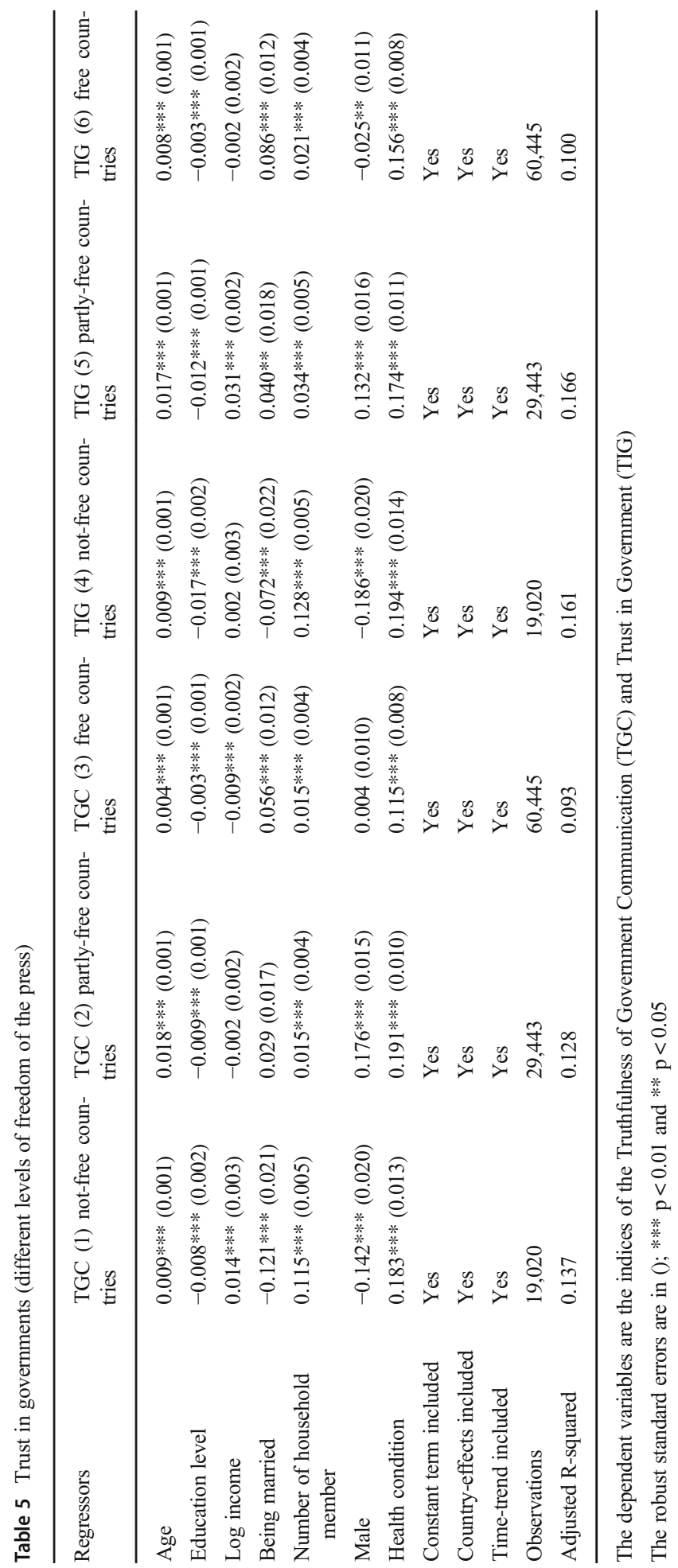




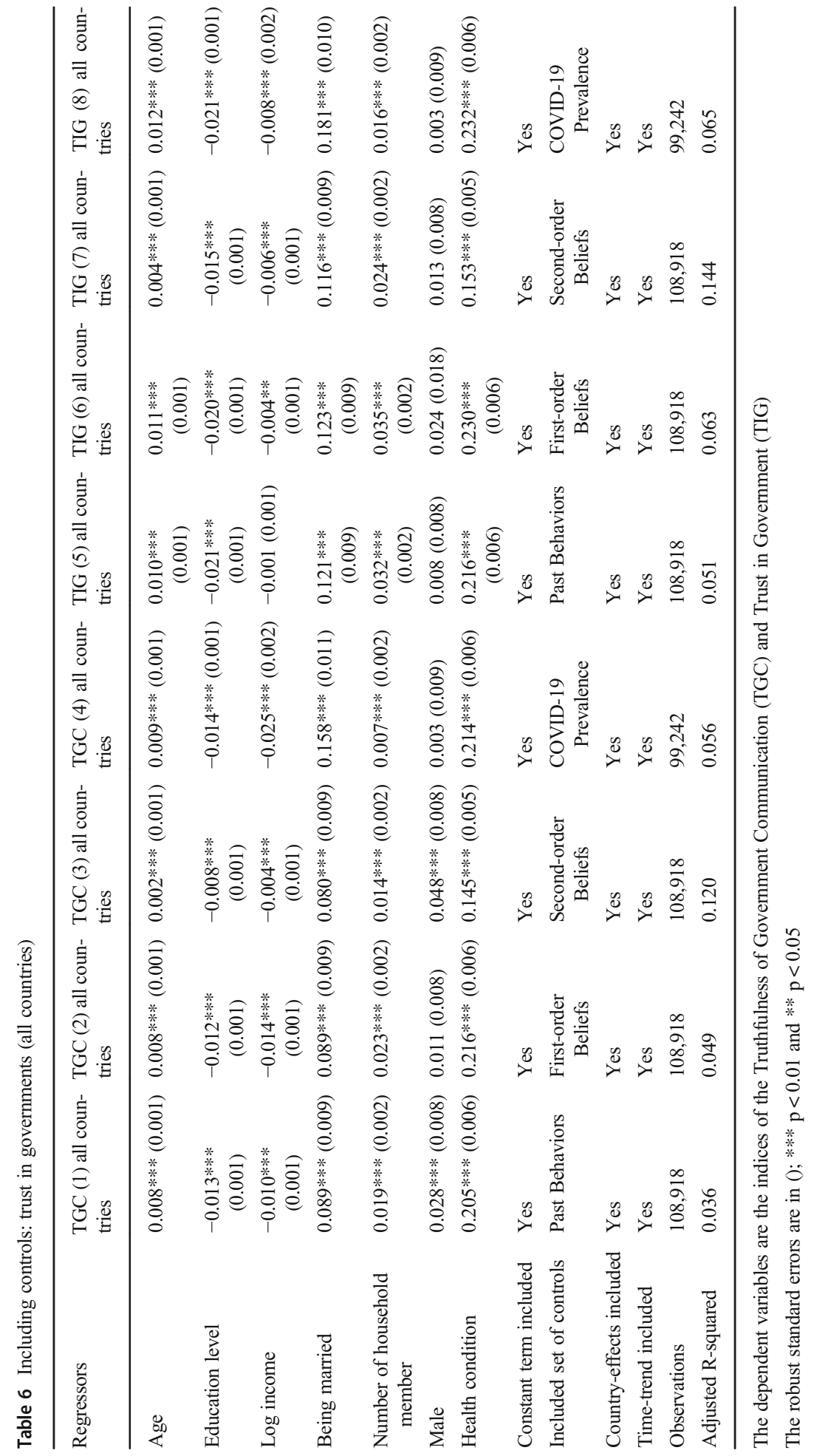




\section{Countries at Different Stages of Economic Development}

The results for countries at different stages of economic development are provided in Table 2. Following the definition of World Bank (2020)'s Country Income and Lending Dataset, we divide the countries in our sample as the "Low-Income and MiddleIncome Economies" and the "High-Income Economies." Columns 1 and 2 report the findings for $T G C$, while Columns 3 and 4 provide the results for $T I G$ for respective income definitions. All results include both the country-effects and the time-trend.

All findings show that age, number of households, and health conditions yield to higher levels of $T G C$ and $T I G$. Education is negatively associated with both $T G C$ and $T I G$. Identifying as male and being married is positively related to both $T G C$ and $T I G$. However, their coefficients are statistically insignificant when different measures of trust in government are considered.

The impact of the log of income on trust in government is mixed; i.e., it depends on the stages of economic development. The mixed findings on the effects of income on trust in government are also in line with the previous findings. For example, Anderson (2010) finds that income is positively related to the trust in government in the United States. However, Zhao and $\mathrm{Hu}$ (2017) observe there is a negative relationship between income and public trust in government in China. These findings suggest that the effects of income on trust in government can be explained via the different stages of economic development. In the next section, we implement additional robustness analyses to check the validity of these main findings.

\section{Robustness Checks}

\section{Countries at Different Levels of Globalization}

The findings for countries at different levels of globalization are reported in Table 3. Using the Revisited KOF Globalization Indices of Gygli et al. (2019), we define the countries in our sample as the "Less-Globalized and Globalized Countries" and the "Hyper-Globalized Countries." The Hyper-Globalized countries are defined as countries; whose globalization index value in the last year is one standard deviation away from the average of all countries in our dataset. The remaining states are labeled as the Less-Globalized and Globalized countries. Columns 1 and 2 report the results for $T G C$, while Columns 3 and 4 provide the findings for $T I G$ for respective globalization definitions. All findings include both the country-effects and the time-trend.

According to the findings, age, number of households, and health conditions increase $T G C$ and $T I G$. Education decreases both $T G C$ and $T I G$. Identifying as male and being married are positively related to both $T G C$ and $T I G$. However, the coefficients are not statistically significant when different measures of trust in government are used. The signs of the coefficients for log income are mixed, i.e., its impact depends on the levels of globalization.

\section{Countries at Different Levels of Institutional Quality}

The results for countries at different levels of institutional quality are provided in Table 4. Following the definition of Freedom House (2020a), we divide the countries 
in our sample as the "Not-Free Countries," the "Partly Free Countries," and the "Free Countries" in terms of their civil liberties and political rights. Columns 1, 2, and 3 reports the results for $T G C$, while Columns 4, 5, and 6 illustrate the findings for $T I G$ for respective definitions. All findings include both the country-effects and the time-trend.

All results state that age and health conditions increase $T G C$ and $T I G$. Education is negatively related to both $T G C$ and $T I G$. The number of households is positively associated with both $T G C$ and $T I G$. However, the coefficients are not statistically significant when different indicators of trust in government are utilized. The effects of being married, log income, and identifying as male on trust in government are somehow mixed, and the findings depend on the different levels of institutional quality.

\section{Countries at Different Levels of Freedom of the Press}

The results for countries at varying levels of freedom of the press are reported in Table 5. Following the definition of Freedom House (2020b), we separate the countries in our sample as "Not-Free Countries," "Partly Free Countries," and "Free Countries" in terms of their freedom of the press. Columns 1, 2, and 3 provide the results for $T G C$, and Columns 4, 5, and 6 report the findings for $T I G$ for respective definitions for the freedom of the press. All results add both the country-effects and the time-trend.

The findings show that age, the number of households, and health conditions increase $T G C$ and $T I G$. Education is negatively associated with $T G C$ and $T I G$. The effects of being married, log income, and identifying as male on trust in government are mixed, and the results significantly change with the different levels of freedom of the press.

\section{All Countries: Including Controls}

In this robustness analysis, we include additional variables to change the effects of personal information on $T G C$ and $T I G$. The results for all countries are reported in Table 6 . We include indicators of precautionary behaviors, first-order beliefs, secondorder beliefs, the COVID-19 prevalence in countries, whose details are discussed in the Data subsection. Here, Columns from 1 to 4 reports the findings for $T G C$, and Columns from 5 to 8 provide the results for $T I G$ by including respective additional controls. All of these findings include both the country-effects and the time-trend.

The results indicate that age, being married, the number of households and health conditions increase $T G C$ and $T I G$. Education is negatively related to both $T G C$ and $T I G$. Log income adversely affects $T G C$ and $T I G$; while identifying as male positively affects $T G C$ and $T I G$. However, their coefficients are statistically insignificant when different measures of trust in government are used.

After various robustness checks, we conclude that older and healthy people trust more to their governments. Education is negatively associated with trust in governments. The results are valid when we use two indicators of trust in governments as well as including various controls. These findings are robust to consider the countries at different stages of economic development as well to consider varying levels of globalization, institutional quality, and freedom of the press.

Overall, demographic indicators explain the public trust in governments during the COVID-19 crisis. We also provide the first evidence for showing the positive effects of the health condition on trust in governments in the COVID-19 era. 


\section{Conclusion}

In this paper, we investigated the determinants of public trust in governments during the COVID-19 era in all around the world. For this purpose, we use the individual-level survey Global Behaviors and Perceptions in the COVID-19 Pandemic dataset at the daily frequency covering 108,918 respondents from 178 countries. We observed that older and healthy people trust more to their governments. Education is negatively correlated with trust in governments. These findings are robust to use different measures of trust in governments and to include various controls, such as precautionary behaviors, first-order beliefs, second-order beliefs, and the COVID-19 prevalence in the country. Another evidence in this paper is that these determinants of public trust in governments are robust to consider the states at different stages of economic development as well to varying levels of globalization, institutional quality, and the freedom of the press.

The findings in this paper show that as long as age increases, public trust in governments also increases. This evidence also means that young people trust less to their governments. Therefore, there is a significant divergence among the generations in terms of trust in governments during the COVID-19. Redistribution among generations can help to increase public confidence in government. Another evidence in this paper is that healthy people trust their governments more. In other words, this evidence means that people with weak health condition trust less to their governments during the COVID-19. Giving that COVID-19 is a health crisis in the early stages, governments should focus on the most vulnerable people. At this stage, more incentives on health expenditures and higher effectiveness in health care for people with poor health conditions can increase the level of trust in governments. Finally, people with higher education trust their governments less. At this point, governments should provide consistent, credible, and transparent communication about the COVID-19 developments. The governments should move their communication channels to different news platforms to enhance the public interest and to gain the trust of educated people.

Our findings are limited to the lockdown of the COVID-19 era, and it is well-known that trust usually increases during crises. However, this effect tends to fade away quickly. Therefore, it would be essential to analyze the dynamics of trust over time. Our findings can be important for future crises. Future papers on the determinants of public trust in governments during the COVID19 can focus on the cases of large developing and developed economies with different outbreak fighting policies, such as China, Sweden, the United Kingdom, and the United States. The disagreement between the government and the opposition for responses to the COVID-19 can also be an interesting research task. For instance, measures of political preferences can be excellent candidates to investigate its impact on public trust in government in the United States during the COVID-19 era. Finally, different regression analysis methods, such as the Least Absolute Shrinkage and Selection Operator (LASSO), can be utilized for the Global Behaviors and Perceptions in the COVID-19 Pandemic dataset.

Acknowledgements I thank Niklas Potrafke, the editor, and the anonymous reviewers for their comments and suggestions, which enhance the paper's merit. 


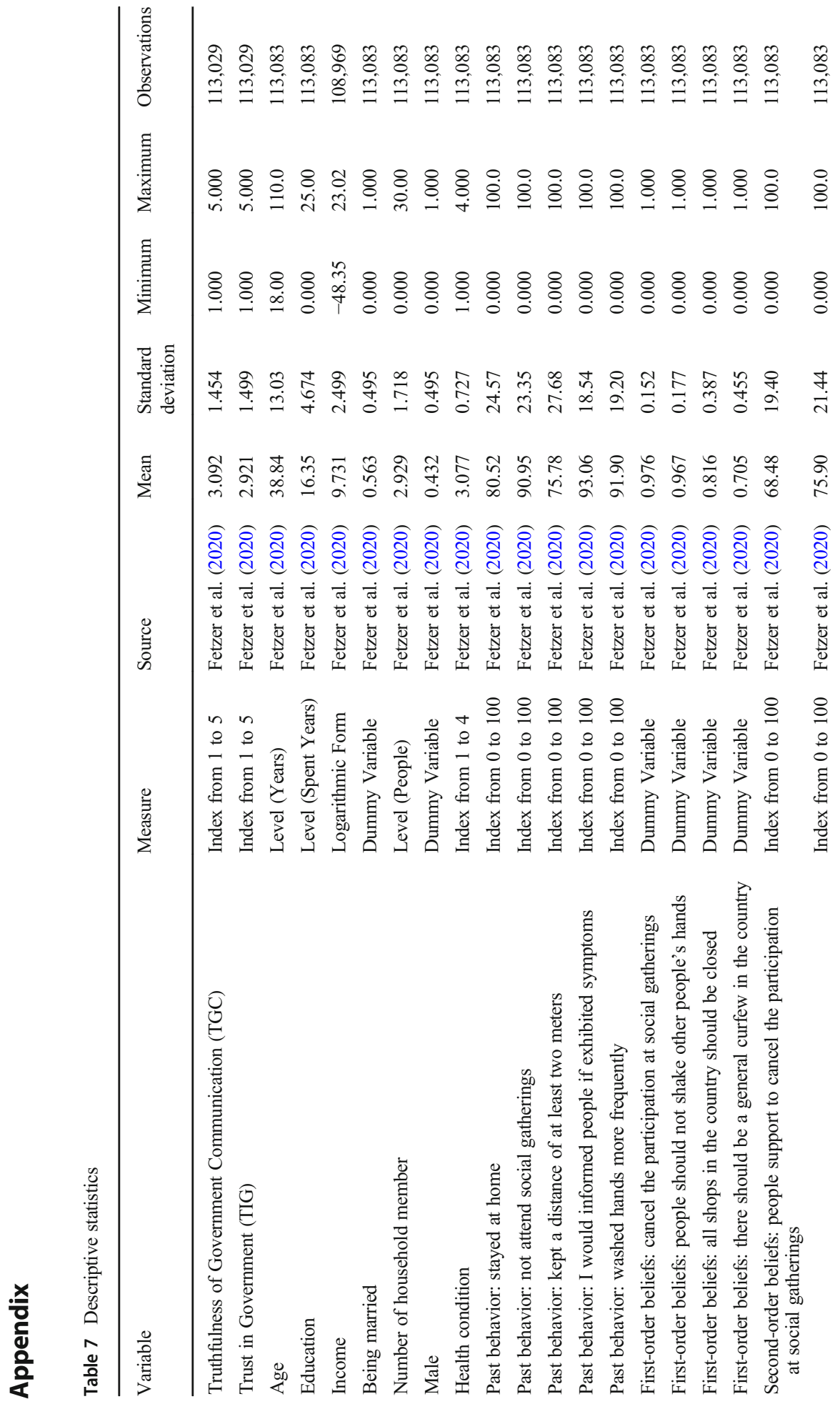




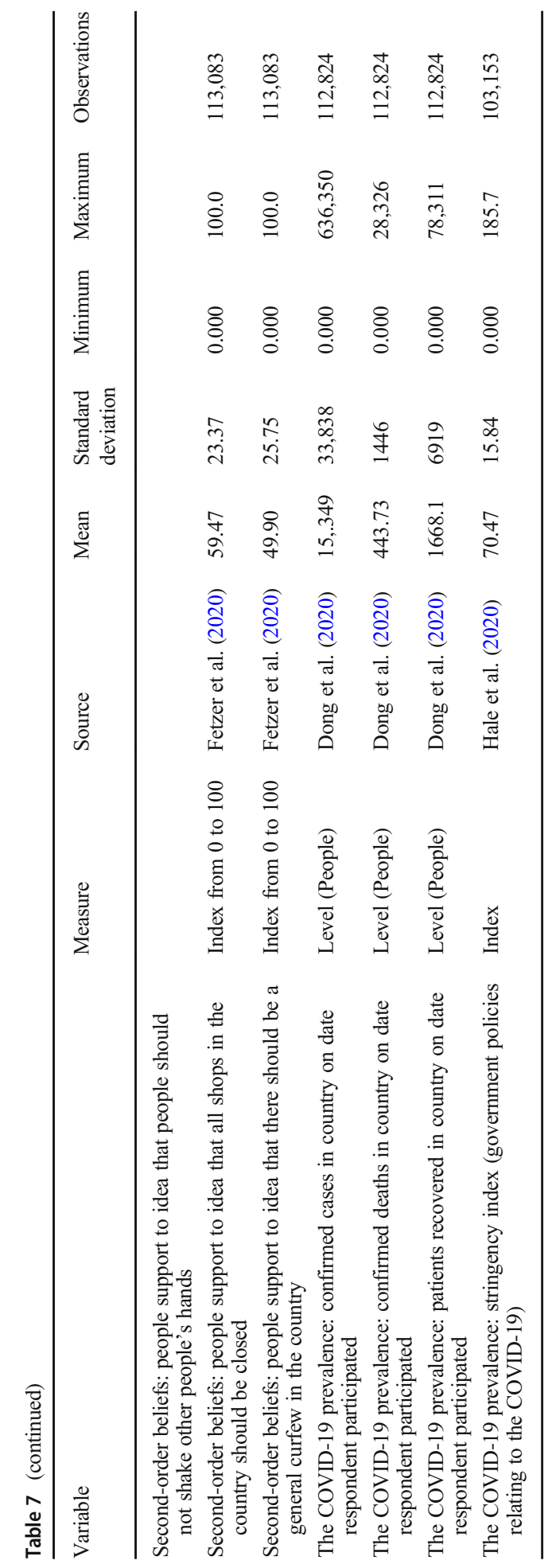


Table 8 Correlation matrix

\begin{tabular}{|c|c|c|c|c|c|c|c|c|c|c|}
\hline Regressors & $\begin{array}{l}\text { Index } \\
\text { of } \\
\text { TGC }\end{array}$ & $\begin{array}{l}\text { Index } \\
\text { of TIG }\end{array}$ & Age & $\begin{array}{l}\text { Education } \\
\text { level }\end{array}$ & $\begin{array}{r}\mathrm{L} \text { o g } \\
\text { income }\end{array}$ & $\begin{array}{l}\text { Being } \\
\text { married }\end{array}$ & $\begin{array}{l}\text { Number } \\
\text { household } \\
\text { member }\end{array}$ & of & Male & $\begin{array}{l}\text { Health } \\
\text { condition }\end{array}$ \\
\hline
\end{tabular}

\begin{tabular}{|c|c|c|c|c|c|c|c|c|c|}
\hline Index of TGC & 1.000 & - & - & - & - & - & - & - & - \\
\hline Index of TIG & 0.754 & 1.000 & - & - & - & - & - & - & - \\
\hline Age & 0.071 & 0.090 & 1.000 & - & - & - & - & - & - \\
\hline $\begin{array}{l}\text { Education } \\
\text { level }\end{array}$ & -0.024 & -0.045 & 0.116 & 1.000 & - & - & - & - & - \\
\hline Log income & -0.010 & -0.011 & 0.039 & 0.073 & 1.000 & - & - & - & - \\
\hline Being married & 0.063 & 0.081 & 0.334 & 0.083 & 0.084 & 1.000 & - & - & - \\
\hline $\begin{array}{c}\text { Number of } \\
\text { household } \\
\text { member }\end{array}$ & 0.024 & 0.042 & -0.120 & -0.030 & 0.102 & 0.125 & 1.000 & - & - \\
\hline Male & 0.015 & 0.005 & 0.036 & 0.012 & 0.062 & 0.056 & 0.002 & 1.000 & - \\
\hline $\begin{array}{l}\text { Health } \\
\text { condition }\end{array}$ & 0.100 & 0.102 & -0.072 & 0.055 & 0.046 & 0.053 & 0.001 & 0.043 & 1.000 \\
\hline
\end{tabular}

Table 9 The countries of respondents in the survey sample (178 countries)

Afghanistan, Albania, Algeria, Andorra, Angola, Argentina, Armenia, Australia, Austria, Azerbaijan, Bahamas, Bahrain, Bangladesh, Barbados, Belarus, Belgium, Belize, Benin, Bhutan, Bolivia, Bosnia and Herzegovina, Botswana, Brazil, Brunei, Bulgaria, Burkina Faso, Cambodia, Cameroon, Canada, Cape Verde, Central African Republic, Chad, Chile, China, Colombia, Congo Republic, Costa Rica, Côte d'Ivoire, Croatia, Cuba, Cyprus, Czech Republic, Democratic Republic of Congo, Denmark, Djibouti, Dominica, Dominican Republic, Ecuador, Egypt, El Salvador, Estonia, Eswatini, Ethiopia, Fiji, Finland, France, Gabon, Gambia, Georgia, Germany, Ghana, Greece, Grenada, Guatemala, Guinea, Guyana, Haiti, Honduras, Hong Kong, Hungary, Iceland, India, Indonesia, Iran, Iraq, Ireland, Israel, Italy, Jamaica, Japan, Jordan, Kazakhstan, Kenya, Kiribati, Korea Republic, Kuwait, Kyrgyzstan, Laos, Latvia, Lebanon, Lesotho, Liberia, Libya, Liechtenstein, Lithuania, Luxembourg, Madagascar, Malawi, Malaysia, Maldives, Mali, Malta, Mauritania, Mauritius, Mexico, Micronesia, Moldova, Monaco, Mongolia, Montenegro,

Morocco, Mozambique, Myanmar, Namibia, Nepal, Netherlands, New Zealand, Nicaragua, Niger, Nigeria, North Korea, North Macedonia, Norway, Oman, Pakistan, Palestine, Panama, Papua New Guinea, Paraguay, Peru, Philippines, Poland, Portugal, Qatar, Romania, Russia, Rwanda, Saint Lucia, Samoa, Saudi Arabia, Senegal, Serbia, Seychelles, Sierra Leone, Singapore, Slovakia, Slovenia, Somalia, South Africa, Spain, Sri Lanka, Sudan, Suriname, Sweden, Switzerland, Syria, Taiwan, Tanzania, Thailand, Togo, Tonga, Trinidad and Tobago, Tunisia, Turkey, Turkmenistan, Uganda, Ukraine, United Arab Emirates, United Kingdom, United States, Uruguay, Uzbekistan, Vanuatu, Venezuela, Vietnam, Yemen, Zambia, and Zimbabwe. 


\section{References}

Acemoglu, D., Naidu, S., Restrepo, P., \& Robinson, J. A. (2019). Democracy does cause growth. Journal of Political Economy, 127(1), 47-100.

Alesina, A., Di Tella, R., \& MacCulloch, R. (2004). Inequality and happiness: Are Europeans and Americans different? Journal of Public Economics, 88(9-10), 2009-2042.

Algan, Y., Cahuc, P., \& Sangnier, M. (2016). Trust and the welfare state: The twin peaks curve. The Economic Journal, 126(593), 861-883.

Anderson, M. R. (2010). Community psychology, political efficacy, and trust. Political Psychology, 31(1), 59-84.

Ariely, G. (2013). Public administration and citizen satisfaction with democracy: Cross-national evidence. International Review of Administrative Sciences, 79(4), 747-766.

Bergh, A., \& Bjørnskov, C. (2011). Historical trust levels predict the current size of the welfare state. Kyklos, 64(1), 1-19.

Chen, J., \& Sun, L. (2019). Media influence on Citizens' government trust: A cross-sectional data analysis of China. International Journal of Public Administration, 42(13), 1122-1134.

Christensen, T., \& Laegreid, P. (2005). Trust in Government: The relative importance of service satisfaction, political factors, and demography. Public Performance and Management Review, 28(4), 487-511.

Cooper, C. A., Gibbs, K. H., \& Kathleen, B. M. (2008). The importance of Trust in Government for public administration: The case of zoning. Public Administration Review, 68(3), 459-468.

Dong, E., Du, H., \& Gardner, L. (2020). An interactive web-based dashboard to track Covid-19 in real time. Baltimore: The Lancet Infectious Diseases, John Hopkins University.

Eichenberger, R., Hegselmann, R., Savage, D. A., Stadelmann, D., \& Torgler, B. (2020). Certified coronavirus immunity as a resource and strategy to cope with pandemic costs. Kyklos, 73(3), 464-474.

Elgin, C., Basbug, G., \& Yalaman, A. (2020). Economic policy responses to a pandemic: Developing the COVID-19 economic stimulus index. Covid Economics: Vetted and Real Time Papers, 3, 40-54.

Ezrow, L., \& Xezonakis, G. (2011). Citizen satisfaction with democracy and Parties' policy offerings. Comparative Political Studies, 44(9), 1152-1178.

Fetzer, T., Witte, M., Hensel, L., Jachimowicz, J. M., Haushofer, J., Ivchenko, A., Caria, S., Reutskaja, E., Roth, C., Fiorin, S., Gomez, M., Kraft-Todd, G., Goetz, F. M., \& Yoeli, E. (2020). Global behaviors and perceptions at the onset of the COVID-19 pandemic. National Bureau of economic research (NBER) working paper, no. 27082. Cambridge: NBER.

Freedom House. (2020a). Freedom in the world (2020th ed.). Washington, D.C.: Freedom House.

Freedom House. (2020b). Freedom of the press excel data. Washington, D.C.: Freedom House.

Gronlund, K., \& Setala, M. (2007). Political trust, satisfaction and voter turnout. Comparative European Politics, 5(4), 400-422.

Gründler, K., \& Krieger, T. (2016). Democracy and growth: Evidence from a machine learning Indicator. European Journal of Political Economy, 45, 85-107.

Gygli, S., Haelg, F., Potrafke, N., \& Sturm, J.-E. (2019). The KOF globalisation index - Revisited. The Review of International Organizations, 14(3), 543-574.

Hale, T., Petherick, A., Phillips, T., \& Webster, S. (2020). Variation in government responses to COVID-19. Oxford: Oxford University.

Kim, S. (2010). Public Trust in Government in Japan and South Korea: Does the rise of critical citizens matter. Public Administration Review, 70(5), 801-810.

Kwon, S. W., Heflin, C., \& Ruef, M. (2013). Community social capital and entrepreneurship. American Sociological Review, 78(6), 980-1008.

Levi, M., \& Stoker, L. (2000). Political trust and trustworthiness. Annual Review of Political Science, 3, 475507.

Norris, P. (1999). Critical citizens: Global support for democratic governance. Oxford: Oxford University.

Norris, P. (2000). A virtuous circle: Political communications in postindustrial societies. Cambridge: Cambridge University Press.

Nye Jr., J. S., Zelikow, P. D., \& King, D. C. (1997). Why people Don't Trust government? Cambridge: Harvard University Press.

Patterson, T. E. (2009). The vanishing voter: Public involvement in an age of uncertainty. New York: Vintage. Potrafke, N. (2015). The evidence on globalisation. The World Economy, 38(3), 509-552.

Rodrik, D. (1998). Why do more open economies have bigger governments? Journal of Political Economy, 106(5), 997-1032. 
Stockmann, D., \& Gallagher, M. E. (2011). Remote control: How the media sustain authoritarian rule in China. Comparative Political Studies, 44(4), 436-467.

Tolbert, C. J., \& Mossberger, K. (2006). The effect of E-government on trust and confidence in government. Public Administration Review, 66(3), 354-369.

Toya, H., \& Skidmore, M. (2014). Do natural disasters enhance societal trust? Kyklos, 67(2), 255-279.

Ulbig, S. G. (2007). Gendering municipal government: Female descriptive representation and feelings of political trust. Social Science Quarterly, 88(5), 1106-1123.

World Bank. (2020). World Bank country and lending groups. Washington, DC: World Bank.

Zhao, D., \& Hu, W. (2017). Determinants of public Trust in Government: Empirical evidence from urban China. International Review of Administrative Sciences, 83(2), 358-377.

Publisher's Note Springer Nature remains neutral with regard to jurisdictional claims in published maps and institutional affiliations. 